\title{
PROFILE OF AMBLYOPIA AND OUTCOME OF OCCLUSION THERAPY IN AMBLYOPIC PATIENTS ATTENDING TERTIARY CARE HOSPITAL OF KATHMANDU
}

\author{
Srijana Karmacharya, Pranisha Singh, Aparna Rizyal and Aditya Prasad Rijal
}

Department of Ophthalmology, Nepal Medical College and Teaching Hospital, Attarkhel, Gokarneshwor-8,

\begin{abstract}
Amblyopia is a common cause of visual impairment in children. The aim of this study was to assess the profile of amblyopia and the outcome of occlusion therapy in amblyopic children attending the eye department of a tertiary care hospital. This was a hospital based prospective interventional study. Sixty-five eyes of 47 patients fulfilling the inclusion criteria were included in the study. Occlusion therapy was started for the diagnosed amblyopic cases after refractive adaptation of 4 weeks. The mean age of presentation was $8.8 \pm 3.2$ years. $29(61.7 \%)$ cases had unilateral amblyopia, 18(38.3\%) cases had bilateral amblyopia. Ametropic amblyopia (52.3\%) was the most common type of amblyopia followed by Anisometropia (23.1\%). Refractive error was the most common cause of amblyopia with compound myopic astigmatism seen among $30.8 \%$ and hypermetropia among $29.2 \%$ of patients. There was no significant association between initial visual acuity with age of presentation and types of amblyopia respectively $(\mathrm{P}=0.1, \mathrm{P}=0.5)$. The final visual outcome after therapy was better among patients with Ametropic amblyopia than other types $(\mathrm{P}=0.02)$. There was significant association between final visual outcome with age, initial visual acuity, type and severity of amblyopia respectively $(\mathrm{P}<0.001$, $\mathrm{P}<0.001, \mathrm{P}=0.02, \mathrm{P}=0.02$ ). In conclusion, Ametropia was the most common type of amblyopia. The mean age of presentation was 8.8 years, which was beyond the critical period affecting the outcome of treatment. Uncorrected refractive error was the most common amblyogenic factor. Age of presentation, types and severity of amblyopia are the important contributing factors for the outcome of occlusion therapy. Therefore, early detection and management of amblyopia is important to reduce visual impairment among children.
\end{abstract}

\section{KEYWORDS}

Amblyopia, Refractive error, occlusion therapy, Nepal

Received on: February 02, 2021

Accepted for publication: March 03, 2021

\section{CORRESPONDING AUTHOR}

Dr. Srijana Karmacharya

Lecturer

Department of Ophthalmology,

Nepal Medical College Teaching Hospital

Attarkhel, Gokarneshwor-8, Kathmandu, Nepal

Email: karmacharya.srijana21@gmail.com

Orcid No: https://orcid.org/0000-0002-2209-7232

DOI: https://doi.org/10.3126/nmcj.v23i2.38505 


\section{INTRODUCTION}

Amblyopia is defined as a unilateral or bilateral decrease in visual acuity caused by deprivation of pattern vision or abnormal binocular interaction without detectable cause. ${ }^{1}$ It is the most common cause of monocular blindness globally. ${ }^{2-4}$ In Nepal, prevalence has been reported to be $0.9-1.8 \% .^{5-7}$ The different causes of amblyopia include strabismus, anisometropia, bilateral high-refractive errors, form deprivation, high astigmatism or a combination of two or more etiologies in the same patient. Though the causes are different, the basic mechanisms of either abnormal binocular interactions between two eyes or form deprivation in one or both eyes remains same in all cases of amblyopia. ${ }^{8-10}$

The mainstay of amblyopia treatment is occlusion therapy with patching of sound eye along with optical correction. Outcome of occlusion treatment depends on age at presentation, types and severity of amblyopia, initial visual acuity and treatment compliance. ${ }^{11}$

In Nepal, few retrospective studies on clinical profile of amblyopia and outcome of occlusion therapy have been reported. This study analyzed the clinical profile of amblyopia and outcome of occlusion therapy in amblyopic children.

\section{MATERIALS AND METHODS}

This prospective, hospital based interventional study was done in outpatient department of Ophthalmology at Nepal Medical College Teaching Hospital (NMCTH) from January 2016 to July 2017. Ethical clearance was taken from Nepal Medical College- Institutional Review Committee (NMC-IRC). Informed consent was taken from the parents before enrolling children in the study. Consecutive sampling method was used in this study. All children below 18 years with the diagnosis of amblyopia were included in this study. Children with stimulus deprivation amblyopia were excluded from the study due to different modalities of treatment for them.

Detailed history regarding age of onset and past occlusion treatment was recorded. Ophthalmic examination included visual acuity by Snellen vision chart, cycloplegic refraction by streak retinoscope. Thorough anterior and posterior segment evaluation was done using Takaji Slit lamp biomicroscopy and indirect ophthalmoscopy. Ocular alignment was assessed by cover-uncover test and prism cover test. Binocularity was assessed by Worth four dot test and synaptophore.

Amblyopia was defined as a reduction of bestcorrected Snellen acuity to less than 6/9 (20/30) in one eye or a two-line difference between the two eyes, with no visible signs of eye disease. ${ }^{12}$

Amblyopia was classified into following different types. ${ }^{13}$

Ametropic: If there is amblyopia in both the eyes with the spherical equivalence of refractive error of more than 1D.

Anisometropic: amblyopia in the presence of anisometropia of 1D of spherical equivalence or the 1.5D of astigmatism. Strabismic: amblyopia in presence of heterotropia at distance/near or history of strabismus surgery in past

Combined: amblyopia in the presence of both strabismus and anisometropia

Stimulus deprivation: patients with known documented cases of sensory deprivation (ptosis, cataract or other media opacities) with no primary heterotopias or refractive error that could be causally related to amblyopia.

Based on visual acuity, Amblyopia was also categorized into different severity: ${ }^{14}$ mild when visual acuity was $6 / 9$ to $6 / 12$, moderate when visual acuity was $6 / 18$ to $6 / 24$ and severe when visual acuity was $6 / 36$ or less. The severity of refractive error was graded as mild, moderate and severe. Mild: when myopia and hyperopia of up to 2D spherical equivalence, astigmatism of 1D, moderate: when hyperopia and myopia of $>2 \mathrm{D}$ to $5 \mathrm{D}$ spherical equivalence, and astigmatism $>1 \mathrm{D}$ to $3 \mathrm{D}$ and high refractive error when myopia and hyperopia of $>5 \mathrm{D}$ spherical equivalence and the astigmatism more than 3D.

All the diagnosed cases of amblyopia were prescribed occlusion therapy along with $2 \mathrm{hrs}$ of near activities after refractive adaptation of 4 weeks. Children with mild to moderate amblyopia were treated with $2 \mathrm{hrs}$ patching of sound eye. For severe amblyopia 6 hours of patching was advised. Cases with Ametropic amblyopia were prescribed patching of alternate eyes. Patching was done using Surgiclude Orthoptic Eye Patch. Follow up was done at 3weeks, 3months and 6months after instituting patching regime. To make sure that patient is adhering to treatment protocol, in every follow-up visit history was taken about the hours of patching being done and the hours of near activities done during patching time. Visual acuity of $6 / 9$ or better in the amblyopic eye or acuity of no more than 1 line worse than sound eye or end of 6 month was considered as end point of treatment. 
Data was collected in research proforma. Data entry and statistical analysis were done using SPSS version 16. Chi square test was used to find the association between categorical variables. $P$ value $<0.05$ was considered significant.

\section{RESULTS}

A total of 65 amblyopic eyes of 47 patients were included in this study. Twenty (42.6\%) of the cases were male while twenty-seven cases (57.4\%) were females. The mean age of the patients was $8.8 \pm 3.2$ years (range 5-16years). Median age was 8 years. Among 47 amblyopic cases, twenty-nine cases $(61.7 \%)$ had unilateral amblyopia, while eighteen cases (38.3\%) had bilateral amblyopia. Among unilateral cases; in $18(38.3 \%)$ cases left eyes were affected and in $11(23.4 \%)$ right eyes were affected (Table 1).

Among 65 amblyopic eyes, the most common type of amblyopia was Ametropic amblyopia (52.3\%, n=34), followed by Anisometropic (23.1\%, $n=15)$, Strabismic $(13.8 \%, n=9)$ and combined type $(10.8 \%, \mathrm{n}=7)$. In our study, the common type of strabismus was Esotropia $(21.3 \%, \mathrm{n}=10)$ followed by Exotropia (10.6\%, $\mathrm{n}=5)$. According to severity; $69.2 \% \quad(\mathrm{n}=45)$ had severe amblyopia, $23.1 \% \quad(n=15)$ had moderate amblyopia and $7.7 \%(n=5)$ had mild

\begin{tabular}{|llcc|}
\multicolumn{2}{|c}{ Table 1: Characteristics of Amblyopic } \\
Pariables & & $\mathbf{n}$ & $\mathbf{\%}$ \\
Gender & Male & 20 & 42.6 \\
& Female & 27 & 57.4 \\
Age & 5-7 years & 21 & 44.7 \\
& 8-10 years & 16 & 34.0 \\
Binocularity & 11-16 years & 10 & 21.3 \\
& Unilateral & 29 & 61.7 \\
& Bilateral & 18 & 38.3 \\
Laterality & Right eye & 11 & 23.4 \\
& Left eye & 18 & 38.3 \\
\hline
\end{tabular}

Table 2: Types and Severity of Amblyopia

\begin{tabular}{llcc} 
Variables & & $\mathbf{n}$ & $\mathbf{\%}$ \\
& Ametropic & 34 & 52.3 \\
Types of & Anisometropic & 15 & 23.1 \\
Amblyopia & Strabismic & 9 & 13.8 \\
& Combined & 7 & 10.8 \\
Severity of & Mild & 5 & 7.7 \\
Amblyopia & Moderate & 15 & 23.1 \\
& Severe & 45 & 69.2 \\
\hline
\end{tabular}

Table 3: Types of Refractive Error in Amblyopic eyes

\begin{tabular}{|lcc|} 
Types of refractive error & $\mathbf{n}$ & $\mathbf{\%}$ \\
No error & 1 & 1.5 \\
Simple Myopia & 2 & 3.1 \\
Simple Myopic astigmatism & 7 & 10.8 \\
Compound Myopic & 20 & 30.8 \\
astigmatism & 19 & 29.2 \\
Simple Hyperopia & 1 & 1.5 \\
Simple Hyperopic & & \\
astigmatism & 8 & 12.3 \\
Compound Hyperopic & 7 & 10.8 \\
\hline astigmatism & & \\
Mixed astigmatism &
\end{tabular}

amblyopia (Table 2). We found that there was no statistically significant association $(\mathrm{P}=0.55)$ between types of amblyopia and visual acuity at presentation. Seventy three percent of cases with Ametropic amblyopia had an initial visual acuity between 6/18-6/36.

The type of refractive error associated with amblyopia was also analyzed (Table 3). Compound myopic astigmatism $(n=20,30.8 \%)$ was most frequently found in amblyopic eyes, followed by hyperopia ( $n=19,29.2 \%)$. Most of them had moderate refractive error (63.1\%, $\mathrm{n}=41)$, followed by severe refractive error (24.6\%, $n=16$ cases). Compound myopic Astigmatism (38.2\%) was significantly ( $\mathrm{P}=0.022)$ higher among those with Ametropic Amblyopia.

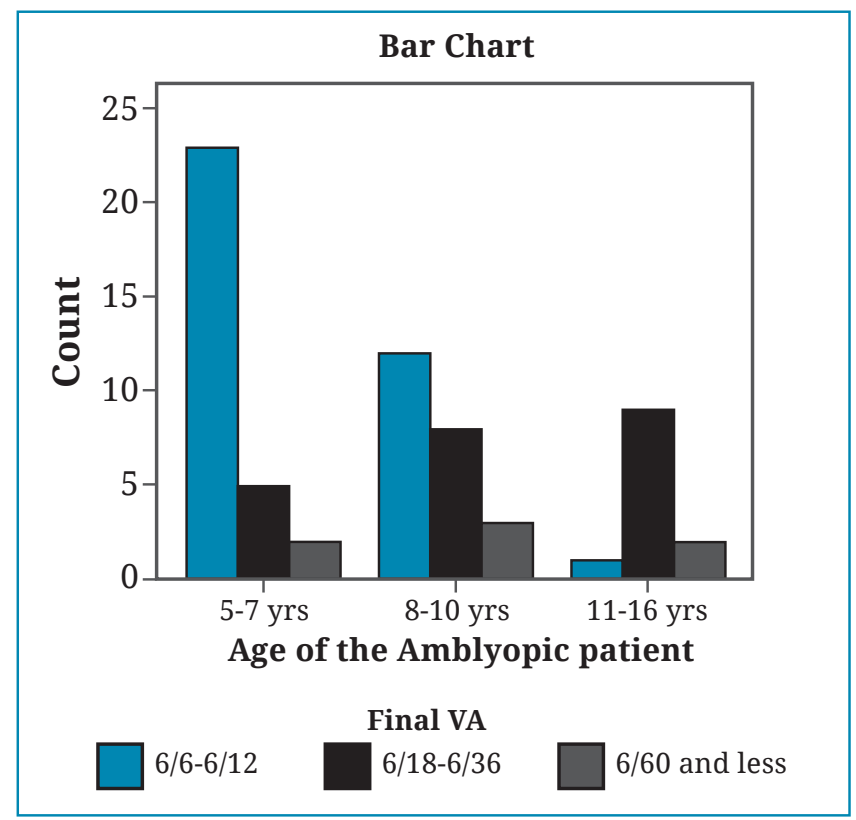

Fig.1: Association between age of presentation and final visual acuity 


\begin{tabular}{|lccccc|}
\hline \multicolumn{5}{|c|}{ Table 4: Association between age at presentation and final visual outcome } \\
\hline $\begin{array}{l}\text { Age of the } \\
\text { Amblyopic }\end{array}$ & $\mathbf{6 / 6 - 6 / 1 2}$ & $\mathbf{6 / 1 8 - 6 / 3 6}$ & $\mathbf{6} / \mathbf{6 0}$ or less & Total & \\
Patient & $\mathbf{n}(\%)$ & $\mathbf{n}(\%)$ & n (\%) & n (\%) & P value $=$ \\
5-7 years & $23(76.7)$ & $5(16.7)$ & $2(6.7)$ & $30(100)$ & 0.002 \\
8-10 years & $12(52.2)$ & $8(34.8)$ & $3(13.0)$ & $23(100)$ & \\
11-16 years & $1(8.3)$ & $9(75.0)$ & $2(16.7)$ & $12(100)$ & \\
\hline
\end{tabular}

\section{Table 5: Association between initial visual acuity and final visual acuity after treatment}

\begin{tabular}{lccccc|}
\hline Initial VA & $\begin{array}{c}\text { Final VA } \\
\text { (6/6-6/12 } \\
\mathbf{n ( \% )}\end{array}$ & $\begin{array}{c}\mathbf{6 / 1 8 - 6 / 3 6} \\
\mathbf{n}(\mathbf{\%})\end{array}$ & $\begin{array}{c}\mathbf{6 / 6 0} \text { or less } \\
\mathbf{n}(\mathbf{\%})\end{array}$ & Total n(\%) & P value \\
$6 / 9-6 / 12$ & $5(100.0)$ & & & $5(100)$ & \\
$6 / 18-6 / 36$ & $29(70.7)$ & $12(29.3)$ & & $41(100)$ & $\mathrm{P}=0.00$ \\
$6 / 60$ or less & $2(10.5)$ & $10(52.6)$ & $7(36.8)$ & $19(100)$ & \\
\hline
\end{tabular}

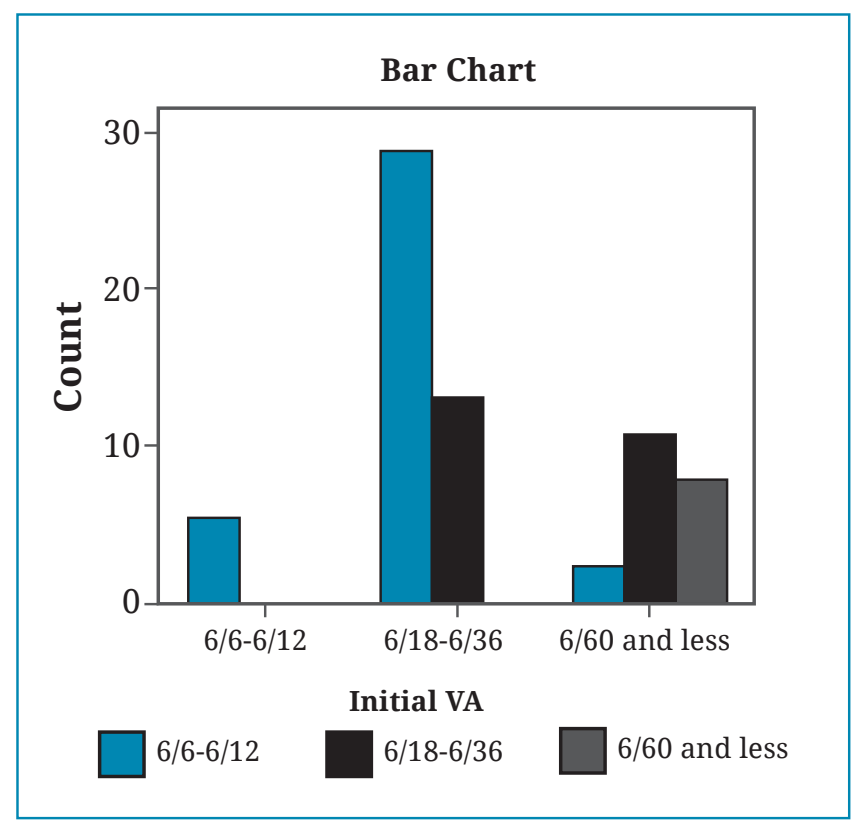

Fig 2: Association between initial visual acuity and final visual acuity after treatment

There was statistically significant association between severity of refractive error and visual acuity at presentation $(\mathrm{P}=0.005)$. 68.3\% of amblyopic eyes with moderate refractive error had visual acuity between 6/18-6/36 at presentation. Fifty six percent of patients with severe refractive error had a visual acuity of $6 / 60$ or less at presentation.

The association between the age of presentation and the visual acuity at presentation was not statistically significant $(\mathrm{P}=0.15)$. However the final visual acuity in relation to age of presentation was found to be significant. $(\mathrm{P}=0.00)$ (Table 4, Fig. 1)

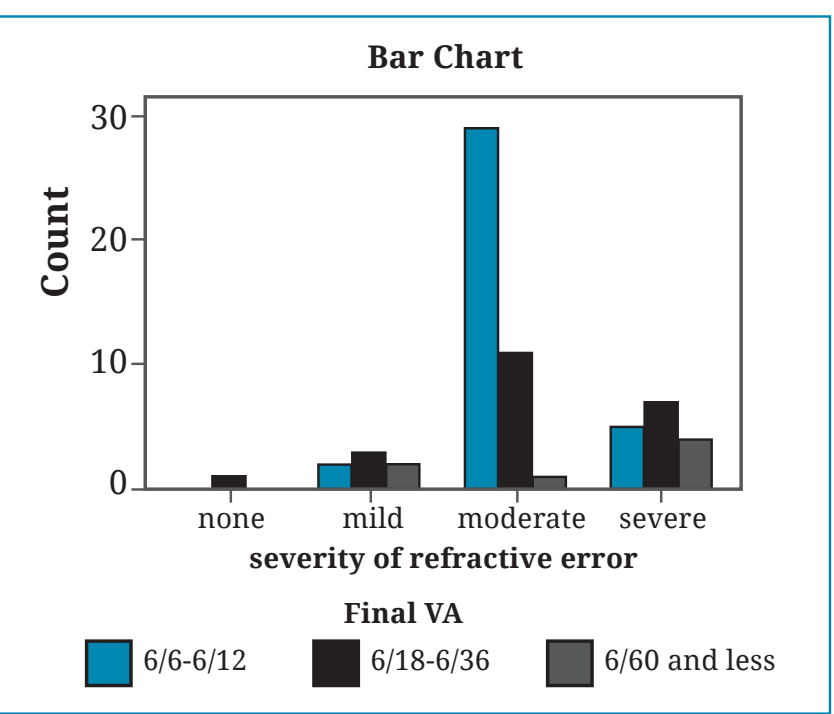

Fig. 3: Severity of Refractive error and Amblyopia

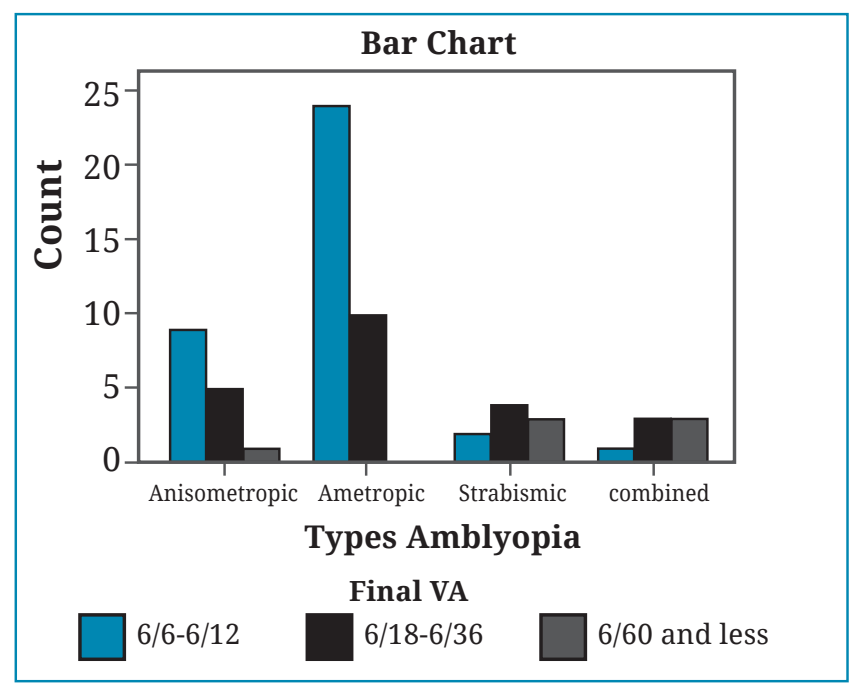

Fig. 4: Association between types of Amblyopia and Final Visual Acuity 
Table 6: Association of Final Visual acuity with severity of Refractive Error

\begin{tabular}{lccccc|} 
Severity of & \multicolumn{4}{c}{ Final Visual acuity } \\
Refractive error & $\mathbf{6 / 6 - 6 / 1 2}$ & $\mathbf{6 / 1 8 - 6 / 3 6}$ & $\mathbf{6 / 6 0}$ or less & $\begin{array}{c}\text { Total } \\
\mathbf{n}(\%)\end{array}$ \\
None & $\mathbf{n}(\mathbf{\%})$ & $\mathbf{n}(\mathbf{\% )}$ & & $1(100)$ & P value $=$ \\
Mild & & $1(100)$ & & $7(100)$ & 0.019 \\
Moderate & $2(28.6)$ & $3(42.9)$ & $2(28.6)$ & $41(100)$ & \\
Severe & $29(70.7)$ & $11(26.8)$ & $1(2.4)$ & $16(100)$ & \\
\hline
\end{tabular}

Table 7: Association of Final Visual acuity with Types of Amblyopia

\begin{tabular}{lccccc} 
Types of Amblyopia & $\begin{array}{c}\mathbf{6 / 6 - 6 / 1 2} \\
\mathbf{n ( \% )}\end{array}$ & $\begin{array}{c}\mathbf{6 / 1 8 - 6 / 3 6} \\
\mathbf{n}(\mathbf{\%})\end{array}$ & $\begin{array}{c}\mathbf{6 / 6 0} \text { or less } \\
\mathbf{n}(\mathbf{\%})\end{array}$ & $\begin{array}{c}\text { Total } \\
\mathbf{n}(\%)\end{array}$ & \\
Anisometrpic & $9(60.0)$ & $5(33.3)$ & $1(6.7)$ & $15(100)$ & P Value $=$ \\
Ametropic & $24(70.6)$ & $10(29.4)$ & & $34(100)$ & 0.02 \\
Strabismic & $2(22.2)$ & $4(44.4)$ & $3(33.3)$ & $9(100)$ & \\
Combined & $1(14.3)$ & $3(42.9)$ & $3(42.9)$ & $7(100)$ & \\
\hline
\end{tabular}

There was statistically significant $(\mathrm{P}=0.00)$ association between visual acuity at presentation and visual acuity after treatment. All of the patients with initial visual acuity ranging from 6/9-6/12 had final visual acuity better than $6 / 12$. About $70.7 \%$ of amblyopic eyes with initial Visual acuity between 6/18$6 / 36$, had final vision better than 6/12. Only $10.5 \%$ of amblyopic eyes with initial vision $6 / 60$ or less had $6 / 12$ or better vision at the end. About $36.8 \%$ of them had a final visual acuity of $6 / 60$ or less (Table 5, Fig. 2).

There was a significant association between severity of refractive error and final visual acuity $(\mathrm{P}=0.019)$. Almost $71 \%$ of amblyopic eyes with moderate refractive error had final visual acuity of $6 / 12$ and better. About $44 \%$ of the patients with severe refractive error had final visual acuity ranging from 6/18-6/36 at the end of treatment (Table 6, Fig. 3).

This study showed statistically significant association between types of amblyopia and treatment outcome in terms of lines of visual acuity improvement $(\mathrm{P}=0.005)$. Among children with Ametropic amblyopia, 29.4\% had 2 lines of improvement, $23.5 \%$ had 4 lines of improvement, $17.6 \%$ had complete resolution and $5.9 \%$ had no improvement. In Anisometropic amblyopia $40 \%$ had 3lines improvement, $13.3 \%$ had 2 lines and 1 line improvement respectively. There was no improvement in $13.3 \%$ of eyes with Anisometropia. In Strabismic amblyopia 55.6\% had no improvement and $11.1 \%$ had complete resolution. In combined type of amblyopia
$57.1 \%$ had no visual improvement and none of the cases had complete resolution. In terms of final visual acuity, $70.6 \%$ of Ametropic and $60.0 \%$ of Anisometropic amblyopia had final visual acuity of $6 / 12$ or better. About $43 \%$ of combined and $33.3 \%$ of Strabismic amblyopia had significantly lower final visual acuity of $6 / 60$ or less at the end of study. $(P=0.002)$ (Table 7, Fig. 4).

The association between the severity of amblyopia and outcome of treatment in terms of lines of visual acuity improvement was also studied. $80 \%$ of mild amblyopic eye had complete resolution and $20 \%$ had 1 line improvement. In moderate amblyopia only $12.2 \%$ had complete resolution and $31.7 \%$ had 2 lines improvement and $14.6 \%$ had no improvement. None of the eyes with severe amblyopia had complete resolution. This was statistically significant $(\mathrm{P}=0.000)$. There was statistically significant association between severity of amblyopia and final visual acuity $(\mathrm{P}=0.02)$. All of those with mild, $80 \%$ with moderate and $42.2 \%$ with severe amblyopia had a final vision equal or better than 6/12. Almost $16 \%$ with severe amblyopia had vision $6 / 60$ or less at the end of 6 months.

\section{DISCUSSION}

Amblyopia is the most common cause of visual impairment in both children and adults. It is an important public health problem as the visual impairment caused by amblyopia is profound and life long if left untreated. ${ }^{15-17}$ 
The prevalence of amblyopia is reported to be $1.3 \%$ to $3.6 \%$ in developed countries. ${ }^{18}$ In Nepal there is no population-based studies on prevalence of amblyopia. However, few studies done in school, hospital and clinical settingin Nepal has reported it be $0.9-1.8 \% .^{5-7}$

Amblyopia is the unilateral or less commonly bilateral loss of vision caused by abnormal visual inputs during a critical period of visual development. The critical period is seen as the period of time during which abnormal visual inputs can result in amblyopia, but it is also the time during which eliminating the abnormal visual inputs and, usually occluding eyes for some period of time can reverse amblyopia. The critical period for developing amblyopia extends up to 8 years. ${ }^{4}$ Therefore, the age of presentation is important for amblyopia diagnosis and management. In our study the mean age of presentation was 8.8 years, ranging from 5-16 years. This shows that there is lack of awareness among people. Therefore, implementing preschool vision screening is very important for diagnosis of amblyopia.

In our study, among 47 amblyopic cases, 42.6\% were males and $57.4 \%$ were females. Unilateral $(61.7 \%, n=29)$ cases were more common than bilateral $(38.3 \%, \mathrm{n}=18)$. Among unilateral cases, left eye $(38.3 \%, n=18)$ were more frequently affected than Right eye $(23.4 \%, n=11)$. Similarly studies done in Nepal by Sapkota et $a l^{19}$ and in Korea by Chung et $a l^{20}$ have reported that unilateral cases more common than bilateral. However, studies done in India by Menon et $a l^{21}$ and Gupta et $\mathrm{al}^{22}$ and a study done in Ethopia by Destaye et $a l^{23}$ have found that bilateral cases more than unilateral.

In our study Ametropic amblyopia (52.3\%, $\mathrm{n}=34$ ) was the most common type of amblyopia followed by Anisometropic (23.1\%, $n=15)$. Studies done by Adhikari et al ${ }^{24}$ and Bhandari et $a l^{7}$ also found Ametropic amblyopia to be the commonest type. In contrary, Anisometropic amblyopia was the most common type of amblyopia in the studies done by Sapkota et $a^{19}$ and Gupta et al. ${ }^{22}$ This may be due to the fact that children are brought to the hospital only when they notice vision blurring. Therefore anisometropic amblyopia may go unnoticed. Only $(13.8 \%, \mathrm{n}=9)$ cases were Strabismic type in our study. Strabismus in our country is generally not considered as an eye disorder and tends to get ignored. Few other studies have reported strabismic amblyopia to be the commonest one. ${ }^{21,25-27}$

In this study most of the cases had severe amblyopia (69.2\%, n=45), followed by moderate
(23.1\%, n=17) and mild amblyopia (7.7\%, n=5) which is similar to a study by Bhandari et al. ${ }^{7}$ This may be due to the fact that in Nepal cases are usually presented late and there is lack of willingness among people to initiate treatment.

Refractive error was the most common risk factor for the development of amblyopia in this study; with Compound myopic astigmatism $(30.8 \%, n=20)$ being the most common type followed by hypermetropia (29.2\%, n=19). Compound myopic Astigmatism (38.2\%) was the most common refractive error among patients with Ametropic Amblyopia, which was statistically significant $(\mathrm{P}=0.022)$. This was similar to a study done by Sapkota et $a l^{19}$, who reported astigmatism to be the most common type of error accounting for 59.2\%. Gupta et $a l^{22}$ and Xiao et $a l^{28}$ also found astigmatism to be the most common type of refractive error. However, studies done by Menon et $a l^{21}$, Adhikari et $a l^{24}$ and Marthala et $a l^{25}$ reported hypermetropia as the most common type of refractive error in children with amblyopia. The association between type and severity of refractive error with final visual acuity was also statistically significant in our study $(\mathrm{P}=$ $0.036, \mathrm{P}=0.019$ respectively), which was similar to studies done by Menon et $a^{29}$ and Awan et $a l .{ }^{30}$

Around $60 \%$ of Ametropic amblyopia presented among those aged between 5-7 years, whereas $50 \%$ of Anisometropic cases presented among aged between $11-16$ years. This was statistically not significant $(\mathrm{P}=0.09)$. This is comparable to a study done by Menon et $a l^{21}$ and in contrast to study by Pediatric Eye Disease Investigator Group (PEDIG) ${ }^{13}$ where children were of younger age group in strabismus. This suggested that Ametropic amblyopia gets early attention as they experience blurring of vision, whereas Anisometropic cases may go unnoticed.

The association between the types of amblyopia and the initial visual acuity was not significant statistically $(\mathrm{P}=0.55)$. But the association between types of amblyopia and final visual acuity was significant statistically $(\mathrm{P}=0.002)$. Final visual outcome was better among Ametropic amblyopia. About $71 \%$ had final visual acuity equal or better than $6 / 12$, whereas visual acuity of 6/60 and less was seen more commonly among children with Strabismic and Combined amblyopia (33.3\% and $42.9 \%$ respectively). This was similar to the study done by Adhikari et $a l^{24}$ but was in contrary to other studies done by Arikan et $a l^{26}$, Lee et $a l^{31}$ and Mohan et al. ${ }^{32}$

We found that the final visual acuity in relation to age of presentation was statistically 
significant $(\mathrm{P}=0.000)$. Studies done by Beardsell et $a l^{33}$ and Woodruff et $a l^{34}$ did not find any association, however Arikan et $a l^{26}$ found the association between the age and the final visual outcome. We also found a statistically significant association between the initial and the final visual acuity. Children having less initial visual acuity showed lower improvement in the final visual acuity. Similarly, other studies done by Adhikari et $a l^{24}$, Beardell et $a l^{33}$, Woodruff et al ${ }^{34}$ and Flynn et $a l^{35}$ have also reported the same.

In our study $78.5 \%$ had VA $6 / 18$ or better after 6 month of occlusion therapy. This is similar to studies done by Arikan et $a l^{26}$, Beardsell et $a l^{33}$, Woodruff et $a l^{34}$ and Flynn et al. ${ }^{35}$ Therefore, we can conclude that occlusion therapy is effective in the treatment of amblyopia. Factors like age at presentation, types and severity of refractive error, types of amblyopia and initial visual acuity at presentation are very important contributing factors for the final visual outcome. The limitations of this study was that the assessment of the compliance of patching therapy was not done, as we prescribed only part time patching in accordance to recommendation by PEDIG studies ${ }^{13}$. Even the follow up period was of 6 months only.
In conclusion, amblyopia is an important cause of visual impairment among children. The most common amblyogenic factor still remains uncorrected refractive error. The occlusion therapy for treatment of amblyopia is effective if instituted early. So early diagnosis and treatment of amblyopia is of utmost importance to avoid visual impairment in children, which can be profound and life long if left untreated. Preschool and school vision screening program should be brought in focus to avoid the socioeconomic burden caused by amblyopia.

\section{ACKNOWLEDGEMENT}

We would like to acknowledge our patients who participated in this study. We would also like to thank our optometrists; Anu Mishal and Jay Sunder for their help in the study.

Source for this Research Fund: None

\section{Conflict of Interest: None}

\section{REFERENCES}

1. Von Noorden GK. Binocular Vision and Ocular Motility: theory and management of strabismus 2001(5th ed.). St Louis: Mosby: 246-47.

2. National Eye Institute, Office of Biometry and Epidemiology. Report on the National Eye Institute's Visual Acuity Impairment Survey Pilot Study. Washington: Department of Health and Human Service.1998.

3. Attebo K, Mitchell P, Cumming R, Smith W, Jolly N, Sparkes R. Prevalence and causes of amblyopia in an adult population. Ophthalmol 1998; 105: 154-59.

4. Wong AM. New concepts concerning the neural mechanisms of amblyopia and their clinical implications. Can J Ophthalmol 2012; 47: 399409.

5. Nepal BP, Koirala S, Adhikary S, Sharma AK. Ocular morbidity in schoolchildren in Kathmandu. Br J Ophthalmol 2003; 87: 531-34.

6. Sapkota YD, Adhikari BN, Pokharel GP, Poudyal BK, Ellwein LB. The prevalence of visual impairment in school children of upper - middle socioeconomic status in Kathmandu. Ophthalmic Epidemiol 2008; 15: 17-23.

7. Bhandari G, Byanju R, Kandel RP. Prevalence and Profile of Amblyopia in Children at Bharatpur Eye Hospital. Ann Pediatr Child Health 2015; 3: 1085
8. Keech RV, Kutschke PJ. Upper age limit for the development of amblyopia. J Pediatr Ophthal Strab 1995; 32: 89-93.

9. Von Noorden GK. Factors involved in the production of amblyopia. Br J Oph 1974; 58: 15864.

10. Harwerth RS, Smith EL, Duncan GC, Crawford ML, Von Noorden GK. Multiple sensitive periods in the development of the primate visual system. Science 1986; 11: 235-8.

11. Chua BE, Johnson K, Martin F. A retrospective review of the associations between amblyopia type, patient age, treatment compliance and referral patterns. Clin Experiment Ophthalmol 2004; 32: 175-79.

12. Wick B, Wingard M, Cotter S, et al. Anisometropic amblyopia: is the patient ever too old to treat? Optom Vis Sci 1992; 69: 866-78.

13. Pediatric Eye Disease Investigator Group. The clinical profile of moderate amblyopia in children younger than 7 years. Arch Ophthalmol 2002; 120: 281-87.

14. American Academy of Ophthalmology Pediatric Ophthalmology/Strabismus Panel. Preferred Practice Pattern Guidelines. Pediatric Eye Evaluations. SanFrancisco, CA: American Academy of Ophthalmology; 2007. 
15. National Society to Prevent Blindness. Vision problems in the U.S. Data analysis. Definitions, data sources, detailed data tables, analysis, interpretation. Publication P-10. New York: National Society to Prevent Blindness, 1980.

16. Simons K, Reinecke RD. Amblyopia screening and stereopsis. In: Helveston EM, ed. Symposium on Strabismus: Transactions of the New Orleans Academy of Ophthalmology. St. Louis: CV Mosby Co., 1978; 15-50.

17. Oliver M, Nawratzki I. Screening of pre-school children for ocular anomalies. II. Amblyopia. Prevalence and therapeutic results at different ages. Br J Ophthalmol 1971; 55: 467-71.

18. Birch EE. Amblyopia and binocular vision. Prog Retin Eye Res 2013; 33: 67-84.

19. Sapkota K, Pirouzian A, Matta NS. Prevalence of amblyopia and patterns of refractive error in the amblyopic children of a tertiary eye care center of Nepal. Nepal J Ophthalmol 2013; 5: 38-44. doi: 10.3126/nepjoph.v5i1.7820. PMID: 23584645.

20. Chung W, Hong S, Lee JB, Han SH. Pattern Visual evoked potential as a predictor of occlusion therapy for amblyopia. Korean J Ophthalmol 2008; 22: 251-54.

21. Menon V, Chaudhuri Z, Saxena R, Gill K, Sachdev MM (2005). Profile of Amblyopia in a Hospital Referral Practice. Indian J Ophthalmol; 53: 22734.

22. Destaye SA, et al. Prevalence and types of amblyopia among primary school children in Gondar town, Northwest Ethiopia.J Ophthalmol 2017; 2: 000124.

23. Gupta M, Rana SK, Mittal SK, Sinha RN. Profile of amblyopia in school going (5-15 years) children at state level referral hospital in Uttarakhand. $J$ ClinDiagn Res 2016; 10: SC09-SC11. doi:10.7860/ JCDR/2016/16026.8866

24. Adhikari S \& Shrestha U. Types of amblyopia and treatment outcome in Nepalese children. Int'l Eye Sci 2013; 14-17. 10.3980/j.issn.16725123.2013.01.03.

25. Marthala H, Kamath G, Kamath M, Kamath SJ. Clinical profile of amblyopia in a tertiary care teaching hospital in Southern India. Indian $J$ Ophthalmol 2017; 65: 258-9.

26. Arikan G, Yaman A, Berk AT. Efficacy of occlusion treatment in amblyopia and clinical risk factors affecting the results of treatment. Strabismus 2005; 13: 63-9.

27. Sethi S, Sethi MJ, Hussain I, Kundi NK. Causes of amblyopia in children coming to ophthalmology outpatient department Khyber Teaching Hospital, Peshawar. J Pak Med Assoc 2008; 58: 125-28.

28. Xiao X, Liu WM, Zhao WX, Wang Y, Zhang YJ. Prevalence of astigmatism in 2023 children with amblyopia. Zhongguo Dang Dai ErKeZaZhi 2011; 13: $462-65$.

29. Menon V, Chaudhuri Z, Saxena R, Gill K, Sachdeva MM. Factors influencing visual rehabilitation after occlusion therapy in unilateral amblyopia in children. Indian J Med Res 2005; 122: 497-505.

30. Awan M, Proudlock FA, Grosvenor D, Choudhuri I, Sarvanananthan N, Gottlob I. An audit of the outcome of amblyopia treatment: a retrospective analysis of 322 children. Br J Ophthalmol 2010; 94: 1007-11.

31. Lee YR, Lee JY. Part - time occlusion therapy for anisometropic amblyopia detected in children eight years of age and older. Korean J Ophthalmol 2006; 20: 171-76.

32. Mohan K, Saroha V, Sharma A. Successful occlusion therapy for amblyopia in 11-15 years old children. I Pediatr Ophthalmol Strabismus 2004; 41: 89-95.

33. Beardsell R, Clarke S, Hill M. Outcome of occlusion treatment for amblyopia. J Pediatr Ophthalmol Strabismus 1999; 36: 19-24.

34. Woodruff G, Hicox FA, Thompson JR, Smith LK. Factors affecting the outcome children treated for amblyopia. Eye 1994; 8: 627- 31.

35. Flynn JT, Schiffman J, FeuerW, Corona A. The therapy of amblyopia: an analysis of the results of amblyopia therapy utilizing the pooled data of published studies. Trans Am Ophthalmol Soc 1998; 96: 431-50. 